\title{
Microstructure and Mechanical Properties in B-Doped Fe-31.9Ni-9.6Co-4.7Ti Alloys
}

\author{
Doyup Lee $^{1} \cdot$ Toshihiro Omori $^{1} \cdot$ Ryosuke Kainuma $^{1}$
}

Published online: 22 April 2016

(C) ASM International 2016

\begin{abstract}
Effects of the addition of boron on grain boundary precipitation, martensitic transformation temperatures, and mechanical properties were investigated for Fe-31.9Ni-9.6Co-4.7Ti alloy sheets. Grain boundary precipitation of the $\eta$-Ni3Ti phase with the D024 structure, which significantly deteriorates the mechanical properties, is effectively suppressed by the addition of a small amount of B. Both the transformation temperature and the thermal hysteresis slightly increase with increasing B composition. Tensile fracture elongation is improved to be about $1.3 \%$ by addition of $0.05 \% \mathrm{~B}$, but no superelastic property was detected in the cyclic stress-strain curve. The features in the mechanical properties are discussed with the texture properties in the sheet specimen.
\end{abstract}

Keywords Mechanical behavior - Thermoleastic - Fe$\mathrm{Ni}-\mathrm{Co}-\mathrm{Ti} \cdot$ Grain boundary precipitation

\section{Introduction}

Ni-Ti-based shape memory alloys (SMAs) exhibiting moderate ductility and an excellent superelastic (SE) strain of over $7 \%$ are used in many products such as cellar phone antennae, spectacle frames, medical guidewires, stents, and so on. However, since the cold-workability of Ni-Ti-based polycrystalline SMAs is insufficient and its material and

Doyup Lee

doyup.lee.q3@dc.tohoku.ac.jp

1 Department of Materials Science, Graduate School of Engineering, Tohoku University, 6-6-02 Aobayama, Sendai, Miyagi 980-8579, Japan fabrication costs are relatively high, its applications to wider fields are impeded [1].

Up to now, some ferrous polycrystalline alloys, such as $\mathrm{Fe}-\mathrm{Mn}-\mathrm{Si}$ [2, 3], Fe-Ni-C [4], and Fe-Ni-Co-Ti [5-8], have been developed as "ferrous SMAs" because their better workability and lower cost are commercially more attractive than those of Ni-Ti-based SMAs. One of the most serious drawbacks of these ferrous SMAs in practical use has been their poor superelasticity due to non-thermoelastic martensitic transformation with a large thermal transformation hysteresis, except in the case of noble ferrous alloys such as $\mathrm{Fe}-\mathrm{Pt}$ and $\mathrm{Fe}-\mathrm{Pd}$ [1]. In 1984, Maki et al. first observed a thermoelastic microstructural behavior at $173 \mathrm{~K}$ in $\gamma / \alpha^{\prime}$ (bct) transformation of a $\mathrm{Fe}$ 31.9Ni-9.6Co-4.7Ti (at. \%) [Fe-33Ni-10Co-4Ti (mass \%)] alloy by the precipitation of a metastable $\gamma^{\prime}-(\mathrm{Ni}, \mathrm{Fe}, \mathrm{Co})_{3} \mathrm{Ti}$ phase with an $L 1_{2}$ structure [6]. According to Maki, the following four factors are necessary to obtain thermoelastic martensitic transformation in ferrous SMAs [1]: (1) high hardness of the matrix, (2) low Ms temperature, (3) low transformation volume change, and (4) large tetragonality of the martensite. Using these guideline, Kokorin et al. have confirmed an SE strain of approximately $0.7 \%$ in a bending test at $240 \mathrm{~K}$ for $\mathrm{Fe}-28.9 \mathrm{Ni}-18.2 \mathrm{Co}-8.3 \mathrm{Ti}$ [Fe30Ni-19Co-7Ti (mass \%)] alloy [7]. However, brittleness due to grain boundary precipitation of an $\eta-\mathrm{Ni}_{3} \mathrm{Ti}$ phase with a $\mathrm{DO}_{24}$ structure restricts the increase of ductility and SE strain, meaning that this alloy is of no practical use.

Recently, a number of research groups have reported three different kinds of ferrous SMAs, $\mathrm{Fe}-\mathrm{Ni}-\mathrm{Co}-\mathrm{Al}$-based alloys (from fcc to bct) [9-20], Fe-Mn-Ga alloy (from L2 1 to $\mathrm{D}_{22}$ ) $[21,22]$, and $\mathrm{Fe}-\mathrm{Mn}-\mathrm{Al}-\mathrm{Ni}$ alloy (from bcc to nano-twinned fcc) [23-28], showing thermoelastic transformation. In case of the $\mathrm{Fe}-\mathrm{Ni}-\mathrm{Co}-\mathrm{Al}$-based and $\mathrm{Fe}-\mathrm{Mn}-$ $\mathrm{Al}-\mathrm{Ni}$ alloys, strengthening of the parent phase resulting 
from fine and coherent precipitates of the $\gamma^{\prime}$ phase with the $L_{2}$ structure and the $\beta$ phase with the $B 2$ structure by aging heat treatment are important to realize thermoelastic transformation and SE properties, respectively. Especially, in $\mathrm{Fe}-\mathrm{Ni}-\mathrm{Co}-\mathrm{Al}-\mathrm{Ta}-\mathrm{B}$ alloy, the polycrystalline sheet specimens strengthened by the $\gamma^{\prime}-(\mathrm{Ni}, \mathrm{Fe}, \mathrm{Co})_{3}(\mathrm{Al}, \mathrm{Ta})$ phase and strongly textured by thermomechanical treatment exhibit large maximum SE strain of about $13.5 \%$, which is approximately twice that of $\mathrm{Ni}-\mathrm{Ti}$ alloy [9]. Furthermore, noted SE strains of more than $4 \%$ were also confirmed in not only $\mathrm{Fe}-\mathrm{Ni}-\mathrm{Co}-\mathrm{Al}-\mathrm{Ta}$ single-crystal alloys [10-14] but also in $\mathrm{Fe}-\mathrm{Ni}-\mathrm{Co}-\mathrm{Al}-\mathrm{Nb}$-based polycrystalline [16] and $\mathrm{Fe}-\mathrm{Ni}-\mathrm{Co}-\mathrm{Al}-\mathrm{Ti}-$ based [17-19] single-crystal alloys, where $\mathrm{Ta}$ is substituted by $\mathrm{Nb}$ and $\mathrm{Ti}$, well known as $\gamma^{\prime}$ stabilizer elements in Ni-based alloys [29]. The addition of $\mathrm{B}$ in $\mathrm{Fe}-\mathrm{Ni}-\mathrm{Co}-\mathrm{Al}$-based singlecrystal alloys is unnecessary because being a nucleation site of grain boundary precipitation, it does not contain grain boundaries, whereas in the case of polycrystalline alloys [9, 16, 18, 20], the addition of a small amount of boron plays an important role in the drastic suppression of the undesirable $\beta$-NiAl B2 phase appearing on grain boundaries. However, improvement of ductility and SE strain is not satisfied only by the addition of boron. As mentioned above, in the case of polycrystalline alloy, the SE strain can be obtained only in strongly textured sheet specimens by suitable thermomechanical treatment. This means that control of the characteristics of the grain boundary, which decreases the fraction of high-angle boundaries, is also important for further suppression of grain boundary precipitation.

In this study, the effects of the addition of boron and thermomechanical treatment on the grain boundary precipitation of the $\eta-\mathrm{Ni}_{3} \mathrm{Ti}$ phase, martensitic transformation temperatures, and mechanical properties were investigated for the Fe-31.9Ni-9.6Co-4.7Ti (at.\%) polycrystalline alloy with relatively low $\mathrm{Co}$ and $\mathrm{Ti}$ compositions, which has been proposed by T. Maki et al. [6].

\section{Experimental Procedures}

Fe-31.9Ni-9.6Co-4.7Ti-(0, 0.02, 0.05, and 0.08)B alloys (at\%) (hereafter notated as 0B, 0.02B, 0.05B, and 0.08B, respectively) were selected for the present study. Cylindroid ingots of $20 \mathrm{~mm}$ in diameter were prepared by induction melting under an argon atmosphere. The ingots were hot-rolled at $1473 \mathrm{~K}$ to a thickness of $14 \mathrm{~mm}$, followed by ice water quenching. And then the top and bottom surfaces were polished to eliminate scale. The specimens with a thickness of $13.5 \mathrm{~mm}$ were cold-rolled to thickness of a $0.2 \mathrm{~mm}$ without intermediate annealing, where the cold-rolling reduction was $98.5 \%$. This rolling procedure was repeated about 105 times. The sheets were solution-treated at $1473 \mathrm{~K}$ for $3 \mathrm{~h}$ to obtain a $\gamma$ singlephase structure and then quenched into ice water. After that this specimen was aged at $873-1073 \mathrm{~K}$ to form the $\gamma^{\prime}$ $(\mathrm{Ni}, \mathrm{Fe}, \mathrm{Co})_{3} \mathrm{Ti}$ phase precipitate in the $\gamma$ phase. Microstructure observation was carried out by optical microscopy and field emission scanning electron microscopy (FE-SEM: JSM-7800F), and the hardness was evaluated by the microhardness test. The mechanical and SE properties were examined by the cyclic tensile test at a strain rate of $1.67 \times 10^{-4} \mathrm{~s}^{-1}$ in a strain control mode using sheet specimens of $60 \mathrm{~mm} \times 1 \mathrm{~mm} \times 0.18 \mathrm{~mm}$ with mirror surface. Tensile strain was measured by monitoring the displacement of gauge length of $30 \mathrm{~mm}$ marked with two lines, by means of non-contact digital video extensometer. The martensitic transformation temperatures were determined in load-free condition by electrical resistivity (ER) measurement using the four-terminal method at a heating and cooling rate of $5 \times 10^{-2} \mathrm{~K} \mathrm{~s}^{-1}$. The determination of crystal structure of the precipitate on grain boundaries was carried out by powder X-ray diffractometry (XRD). The powder specimens of $0,0.02$, and $0.05 \mathrm{~B}$ with approximately $5 \mu \mathrm{m}$ in diameter were prepared with a flat diamond file and aged at $973 \mathrm{~K}$ for $6 \mathrm{~h}$ after annealing at $1473 \mathrm{~K}$ for $5 \mathrm{~min}$, followed by quenching to ice water. The crystalline orientation was examined by Electron Back-Scatter Diffraction (EBSD).

\section{Results and Discussion}

\section{Microstructures and Vickers Hardness}

Figure 1 shows the microstructures of (a) 0B, (b) $0.02 \mathrm{~B}$, and (c) $0.05 \mathrm{~B}$ specimens aged at $973 \mathrm{~K}$ for $6 \mathrm{~h}$ and (d) $0.08 \mathrm{~B}$ specimen as-solution treated at $1473 \mathrm{~K}$. While the grain boundary precipitates are observed in the $\mathrm{OB}$ specimen, the precipitation along grain boundaries is effectively suppressed in the $0.02 \mathrm{~B}$ and $0.05 \mathrm{~B}$ specimens. Especially, the contrast of grain boundary in the $0.05 \mathrm{~B}$ specimen is the weakest of all. The grain boundary precipitates, however, were confirmed by SEM observation using back-scattering electron (BSE) with a higher magnification even in the $0.05 \mathrm{~B}$ specimen, as shown in the inset of Fig. 1c. On the other hand, in the 0.08B alloy, the liquid phase already appears at the solution-treatment temperature of $1473 \mathrm{~K}$, surrounding the $\gamma$ matrix phase, caused by a decrease of solidus temperature.

In order to confirm the crystal structure of the grain boundary precipitates, powder samples underwent XRD measurement. Figure 2 shows the powder XRD patterns of the $0 \mathrm{~B}, 0.02 \mathrm{~B}$, and $0.05 \mathrm{~B}$ specimens aged at $973 \mathrm{~K}$ for $6 \mathrm{~h}$. While for the $0.02 \mathrm{~B}$ and $0.05 \mathrm{~B}$ alloys, the low fraction of 
Fig. 1 Microstructures of a $0 B$, b $0.02 \mathrm{~B}$, and c $0.05 \mathrm{~B}$ specimens aged at $973 \mathrm{~K}$ for $6 \mathrm{~h}$ and d $0.08 \mathrm{~B}$ specimen solutiontreated at $1473 \mathrm{~K}$. Inset of $\mathbf{c}$ : BSE micrograph for $0.05 \mathrm{~B}$ showing grain boundary precipitation
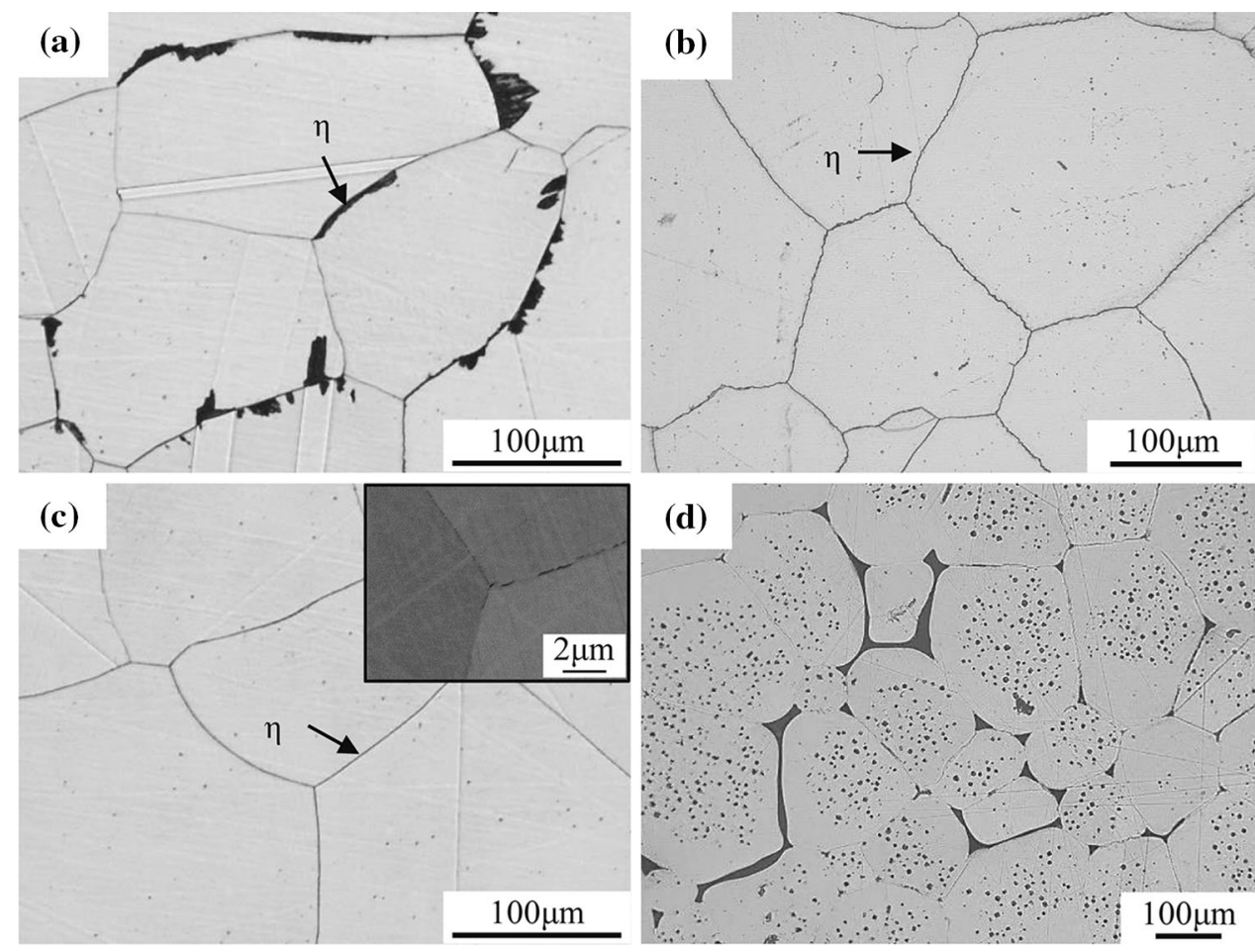

the grain boundary precipitate was not detected, the grain boundary phase of the $0 \mathrm{~B}$ specimen was confirmed as being the $\eta-D O_{24}$ phase, as reported by T. Maki et al. [6]. Thus, it is concluded that grain boundary precipitation is most effectively suppressed by the addition of 0.05 at. \% boron as well as in the case of the $\mathrm{Fe}-\mathrm{Ni}-\mathrm{Co}-\mathrm{Al}$ alloys [9, $16,18,20]$, without formation of the liquid phase at grain boundaries. It is well known that the grain boundary segregation of boron strengthens grain boundaries in Ni-based and Fe-based superalloys [30]. The segregated boron is considered to lower the grain boundary energy, resulting in suppression of precipitation in the present $\mathrm{Fe}-\mathrm{Ni}-\mathrm{Co}-\mathrm{Ti}$ alloys.

It has been reported that a high level of hardness is required to obtain thermoelastic transformation in ferrous SMAs [1]. Vickers hardness of the 0, 0.02, and 0.05B alloys at 873,973 , and $1073 \mathrm{~K}$ is shown in Fig. 3. Vickers hardness of the alloy aged at 873 and $973 \mathrm{~K}$ monotonically increases with aging time as reported by Maki et al. [6], and aging at $973 \mathrm{~K}$ was found to most effectively enhance the hardness in contrast to aging at other temperatures. In a specimen aged at $1073 \mathrm{~K}$, however, the hardness immediately increases and reaches maximum at $1 \mathrm{~h}$ and then gradually decreases. This behavior may be caused by loss of the lattice coherency between the $\gamma$ and $\gamma^{\prime}$ phases, due to coarsening of $\gamma^{\prime}$ precipitates by over-aging. In Fig. 3, it is also seen that the Vickers hardness of all the samples aged at 873 and $973 \mathrm{~K}$ slightly increases with increasing B composition, which may be due to solution hardening.

\section{Transformation Temperatures and Mechanical Properties}

Figure 4 shows the ER curves for the $0 \mathrm{~B}, 0.02 \mathrm{~B}$, and $0.05 \mathrm{~B}$ alloy specimens after aging treatment at $973 \mathrm{~K}$ for $6 \mathrm{~h}$, the hardness level being around $450 \mathrm{Hv}$ as presented in Fig. 3 . In all the samples, the martensitic transformation obviously appears and both the martensitic transformation starting temperature, $M_{\mathrm{s}}$, and the reverse transformation finishing temperature, $A_{\mathrm{f}}$, which are defined as shown in Fig. 4, increase by the addition of boron. Moreover, the thermal hysteresis given by $A_{\mathrm{f}}-M_{\mathrm{s}}$ also increases, reaching the largest value of about $34 \mathrm{~K}$ for the $0.05 \mathrm{~B}$ alloy specimen. It is important to note that for the $0.02 \mathrm{~B}$ and $0.05 \mathrm{~B}$ alloys, the heating curve does not coincide with the cooling curve in the parent phase region, which means that some amount of the martensite phase remains in the temperature range above the $A_{\mathrm{f}}$ temperature. This is obviously related to the increase of the thermal hysteresis with increasing $B$ content and may be caused by local stabilization for some amount of the martensite phase due to the introduction of dislocations. However, this result is apparently in discrepancy with the fact that the specimen with a higher content of $\mathrm{B}$ has a higher hardness, as shown in Fig. 3. The reason for this discrepancy is not clear.

Figure 5 shows the tensile stress-strain curves at $246 \mathrm{~K}$ of the $0 \mathrm{~B}, 0.02 \mathrm{~B}$, and $0.05 \mathrm{~B}$ alloy specimens aged at $973 \mathrm{~K}$ for $6 \mathrm{~h}$ after solution treatment, where the test temperature is higher than $A_{\mathrm{f}}$ temperature of each specimen. It can be 


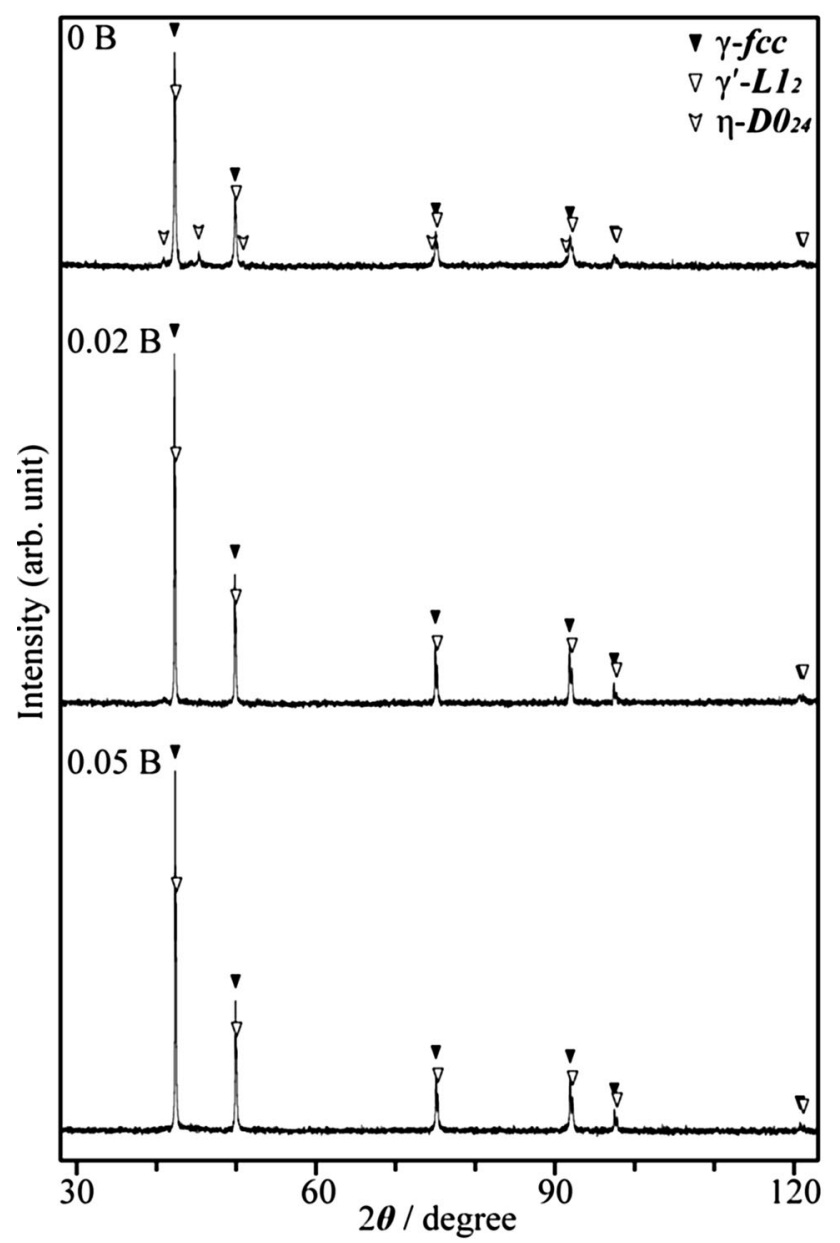

Fig. 2 Powder XRD patterns of the 0B, 0.02B, and 0.05B alloys aged at $973 \mathrm{~K}$ for $6 \mathrm{~h}$

seen that the $0.05 \mathrm{~B}$ alloy specimen shows the highest elongation of about $1.3 \%$ and the highest fracture stress of $784 \mathrm{MPa}$, whereas the elongation and the fracture stress in the other specimens are limited up to only $0.3 \%$ and about 500-550 MPa, respectively. Since the degree of grain boundary precipitation in the $0.05 \mathrm{~B}$ is clearly low, this result must be brought about by the increase of grain boundary strength due to suppression of the precipitation of the $\eta$ phase at grain boundaries. The critical stress for stress-induced martensitic (SIM) transformation, $\sigma c$, which is defined with $0.2 \%$ proof stress, decreases with increase of the martensitic transformation temperatures by $\mathrm{B}$ addition. This fact suggests that the martensite was stress-induced in the tensile test. If being independent of B content in this alloy system, the temperature dependence of critical stress, $\partial \sigma c / \partial T$, can be estimated to be $3.0 \mathrm{MPa} \mathrm{K}^{-1}$ by the Clausius-Clapeyron relation with the differences in the $M \mathrm{~s}$ temperature and the critical stress at $246 \mathrm{~K}$ of each specimen listed in Table 1. This value is almost the same as that

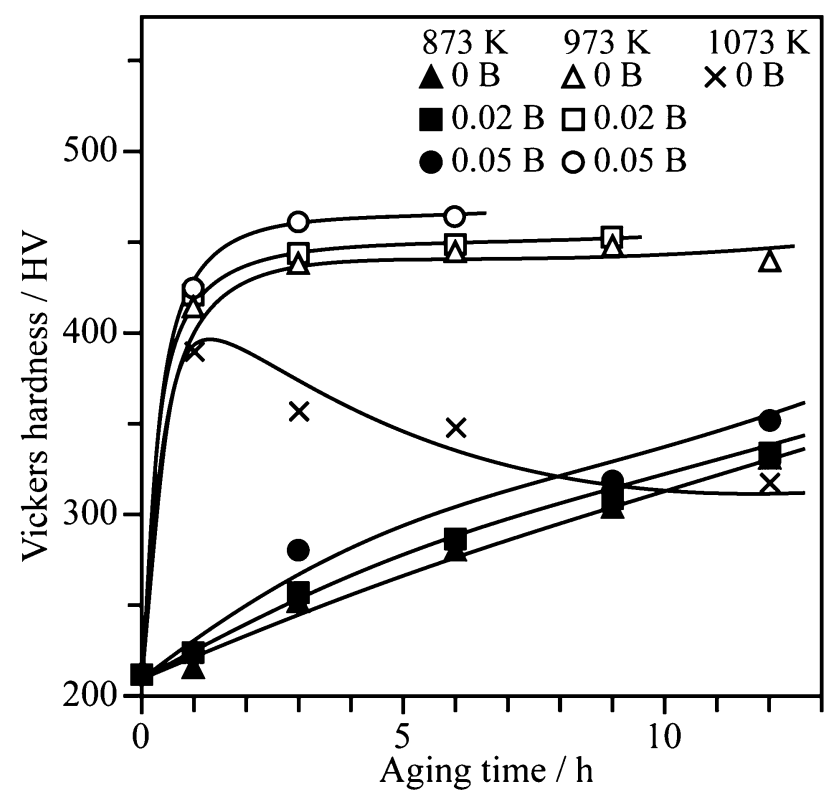

Fig. 3 Vickers hardness of 0, 0.02, and 0.05B alloys aged at 873, 973 , and $1073 \mathrm{~K}$ for several lengths of time

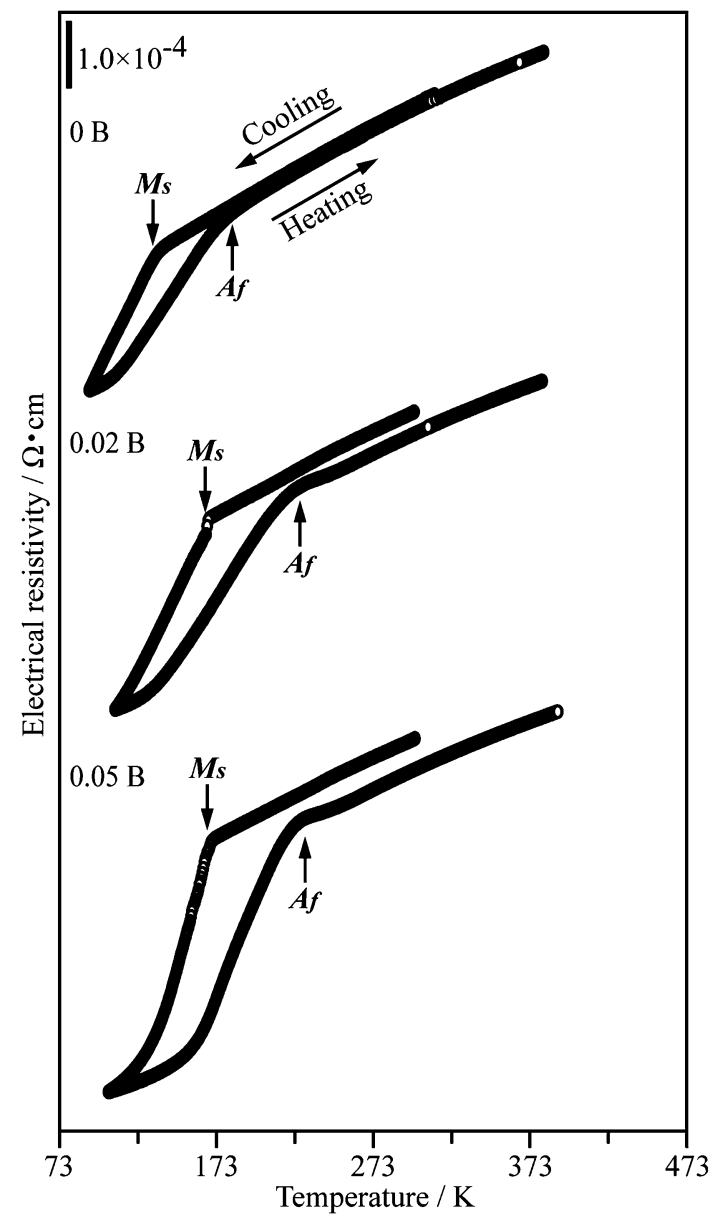

Fig. 4 Electrical resistivity curves during cooling and heating for $0 \mathrm{~B}$, $0.02 \mathrm{~B}$, and $0.05 \mathrm{~B}$ specimens aged at $973 \mathrm{~K}$ for $6 \mathrm{~h}$ 


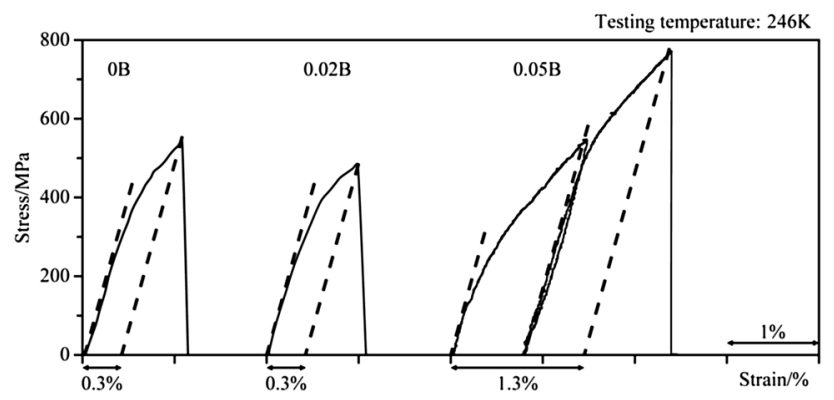

Fig. 5 Tensile stress-strain curves at $246 \mathrm{~K}$ for the 0B, 0.02B, and $0.05 \mathrm{~B}$ alloy sheets aged at $973 \mathrm{~K}$ for $6 \mathrm{~h}$ after annealing at $1473 \mathrm{~K}$ for $3 \mathrm{~h}$

Table 1 Summary of Ms temperature and critical stress for stressinduced martensitic transformation at $246 \mathrm{~K}$ of each specimen aged at $973 \mathrm{~K}$ for $6 \mathrm{~h}$

\begin{tabular}{lll}
\hline & $M_{\mathrm{s}}$ temperature/K & Critical stress for transformation/MPa \\
\hline 0 B & 135 & 465 \\
0.02 B & 168 & 420 \\
0.05 B & 172 & 315 \\
\hline
\end{tabular}

in the $\mathrm{Fe}-\mathrm{Ni}-\mathrm{Co}-\mathrm{Al}-\mathrm{Ta}-\mathrm{B}$ alloy [23] and about half of that in the Fe-28.9Ni-18.2Co-8.3Ti alloy [7].

Since the $A_{\mathrm{f}}$ of the $0.05 \mathrm{~B}$ alloy is about $226 \mathrm{~K}$, SE behavior can be expected in this test. An apparent SE behavior, however, could not be detected. Since the SIM transformation may occur as mentioned above, the steep slope of stress instead of a plateau suggests that the dislocations are introduced during the transformation. Therefore, no obvious SE behavior in the present alloy is probably caused by stabilization of martensite due to introduction of dislocations. In the case of $\mathrm{Fe}-\mathrm{Ni}-\mathrm{Co}-\mathrm{Al}-$ Ta-B alloy fabricated with a similar thermomechanical treatment, dramatic improvements of both ductility and SE properties were realized by the strong $\{035\}<100>$ texture, reaching about 20 and $13.5 \%$, respectively. In order to discuss the difference from the $\mathrm{Fe}-\mathrm{Ni}-\mathrm{Co}-\mathrm{Al}-\mathrm{Ta}-\mathrm{B}$ alloy, the texture properties were examined by EBSD analysis.

\section{Recrystallization Texture}

Figure $6 \mathrm{a}, \mathrm{b}$ shows the quasi-colored orientation maps and (100) pole figure in a $98.5 \%$ cold-rolled sheet specimen of $0.05 \mathrm{~B}$ alloy after solution treatment at $1473 \mathrm{~K}$ followed by quenching to ice water, respectively. Although a high reduction ratio of cold-rolling was carried out, the obtained recrystallization texture near $\left\{\begin{array}{lll}1 & 6 & 10\end{array}\right\}<4 \quad 1 \quad 1>$, tilted by $18^{\circ}-20^{\circ}$ from $\{035\}<100>$, is not so strong, which may be insufficient to suppress grain boundary precipitation, as shown in Fig. 1c. Here, the fractions of low-angle and
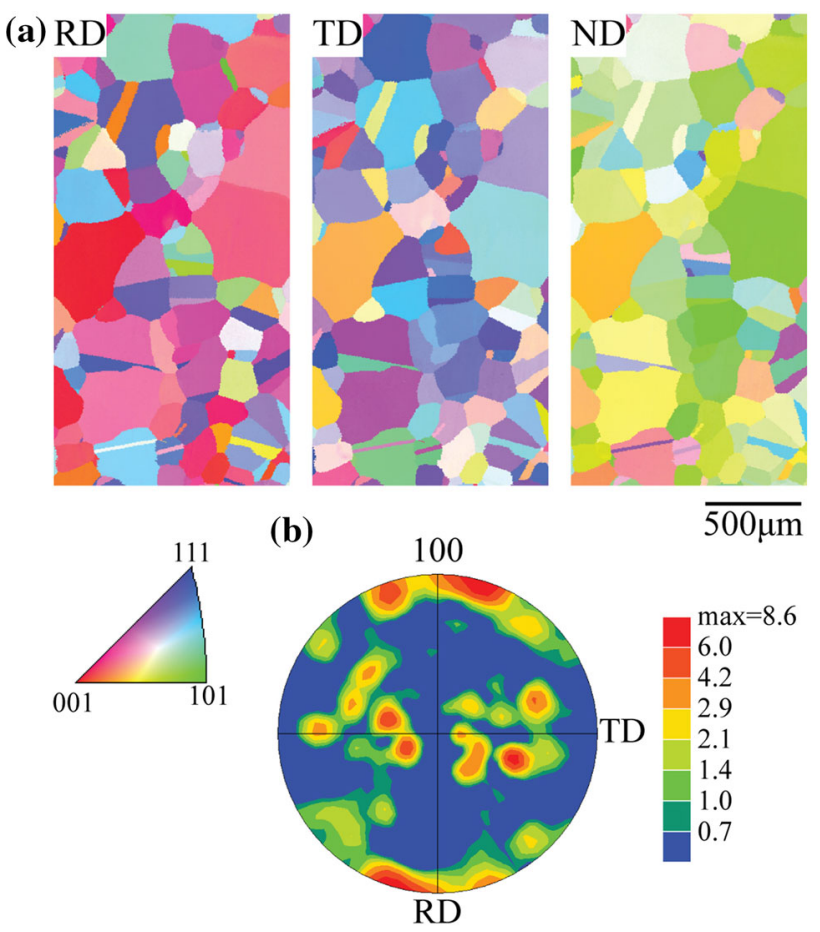

Fig. 6 a Quasi-colored orientation maps in RD, TD, and ND and b (100) pole figure taken from the sheet cold-rolled about $98.5 \%$ after annealing at $1473 \mathrm{~K}$ for $3 \mathrm{~h}$

coincidence site lattice boundaries were evaluated as being about 13 and $7 \%$, respectively, which are much lower than those (60 and $10 \%$, respectively) in the strongly textured $\mathrm{Fe}-\mathrm{Ni}-\mathrm{Co}-\mathrm{Al}-\mathrm{Ta}-\mathrm{B}$ alloy [9]. It is known that grain boundary precipitation, which makes the grain boundaries brittle, can be suppressed by increasing the fraction of the low-energy boundaries such as low-angle and coincidence site lattice boundaries [31]. The lower level of the fracture strain in the present alloy obviously results from the high fraction of the high-energy random boundaries.

It is also known that the SE properties are influenced by strength and crystalline orientation [9]. The absence of SE strain in the present alloy may be brought about by the weak texture. On the other hand, Kokorin et al. have reported a faint SE strain at $240 \mathrm{~K}$ by bending test using the hot-forged Fe-28.9Ni-18.2Co-8.3Ti alloy sheet [7], where the texture seems to be weak. Their alloy has a composition different from that in the present alloy, including higher contents of $\mathrm{Co}$ and $\mathrm{Ti}$. Because the obviously result in the increase of volume fraction of the $\gamma^{\prime}$ precipitates, the higher Co and $\mathrm{Ti}$ contents must make the alloy harder than in the case of the present alloy and improve the SE properties. Further systematic investigations for alloys with different $\mathrm{Co}$ and $\mathrm{Ti}$ contents are required to obtain improvement in SE and mechanical properties of the $\mathrm{Fe}-\mathrm{Ni}-\mathrm{Co}-\mathrm{Ti}-\mathrm{B}$ alloy. 


\section{Summary}

For Fe-31.9Ni-9.6Co-4.7Ti alloys, the effects of the addition of $\mathrm{B}$ and thermomechanical treatment on microstructure and mechanical properties were investigated and the following results were obtained:

1. The grain boundary precipitation of the $\eta$ phase during aging treatment obviously decreases with increasing B composition, being successfully restrained especially in the 0.05 at.\% B alloy, while not being perfectly suppressed.

2. Vickers hardness monotonically increases with aging time in the alloys aged at 873 and $973 \mathrm{~K}$, whereas it suddenly increases initially and then gradually decreases in that aged at $1073 \mathrm{~K}$. Vickers hardness slightly rises with increasing $\mathrm{B}$ composition, reaching approximately $450 \mathrm{Hv}$ by aging at $973 \mathrm{~K}$.

3. Martensitic transformation temperatures and thermal hysteresis in the alloys aged at $973 \mathrm{~K}$ for $6 \mathrm{~h}$ gradually increase by the addition of B. For the 0.02B and 0.05B alloys, the heating curve does not coincide with the cooling one in the parent phase region. This suggests a partial stabilization of the martensite phase.

4. The tensile fracture elongation and fracture stress of the $0.05 \mathrm{~B}$ alloy sheet aged at $973 \mathrm{~K}$ for $6 \mathrm{~h}$ are $1.3 \%$ and $784 \mathrm{MPa}$, respectively, and no SE property could be detected in the tensile stress-strain curve. This may be caused by lack in hardness and texture in the alloy sheets with low contents of Co and Ti. Temperature dependence of critical stress in present alloy is estimated as being 3.0 $\mathrm{MPa} \mathrm{K}^{-1}$.

Acknowledgments This study was supported by a Grant-in-Aid from the Japanese Society for the Promotion of Science (JSPS) and by a Grant for Excellent Graduate Schools, Tohoku University, MEXT, Japan.

\section{References}

1. Otsuka K, Wayman CM (eds) (1998) Shape memory materials. Cambridge University Press

2. Sato A, Chishima E, Soma K, Mori T (1982) Shape memory effect in $\gamma \rightleftarrows \varepsilon$ transformation in Fe-30Mn-1Si alloy single crystals. Acta Metall 30:1177-1183

3. Kajiwara S, Liu D, Kikuchi T, Shinya N (2001) Remarkable improvement of shape memory effect in $\mathrm{Fe}-\mathrm{Mn}-\mathrm{Si}$ based shape memory alloys by producing $\mathrm{NbC}$ precipitates. Scr Mater. 44:2809-2814

4. Kajiwara S, Kikuchi T (1990) Shape memory effect and related transformation behavior in $\mathrm{Fe}-\mathrm{Ni}-\mathrm{C}$ alloys. Acta Metall 38:847-855

5. Ganzula NN, Koval YN, Kokorin VV (1979) Tetragonality of the martensite lattice and characteristics of the gamma if and only if alpha transformation in decomposed substitutional solid solutions. Phys Met Metall 47(4):186-189
6. Maki T, Kobayashi K, Minato M, Tamura I (1984) Thermoelastic martensite in an ausaged $\mathrm{Fe}-\mathrm{Ni}-\mathrm{Co}-\mathrm{Ti}$ alloy. Scr Metall 18:1105-1109

7. Kokorin VV, Samsonov YuI, Chernenko VA, Shevchenko OM (1989) Superelasticity in Fe-Ni-Co-Ti alloys. Phys Met Metall 67(5):202-204

8. Kakeshita T, Shimizu K, Maki T, Tamura I, Kijima S, Date M (1985) Magnetoelastic martensitic transformation in ausaged $\mathrm{Fe}-$ Ni-Co-Ti alloy. Scr Metall 19:973-976

9. Tanaka Y, Himuro Y, Kainuma R, Sutou Y, Omori T, Ishida K (2010) Ferrous polycrystalline shape memory alloy showing huge superelasticity. Science 327:1488-1490

10. Kireeva IV, Chumlyakov YI, Kirillov VA, Kretinina IV, Danil'son YN, Karaman I, Cesari E (2011) Thermoelastic $\gamma-\alpha^{\prime}$ martensitic transformations in FeNiCoAlTa aging single crystals. Russ Phys J 53:1103-1106

11. Evirgen A, Ma J, Karaman I, Luo ZP, Chumlyakov YI (2012) Effect of aging on the superelastic response of a single crystalline FeNiCoAlTa shape memory alloy. Scr Mater. 67:475-478

12. Ma J, Hornbuckle BC, Karaman I, Thompson GB, Luo ZP, Chumlyakov YI (2013) The effect of nanoprecipitates on the superelastic properties of FeNiCoAlTa shape memory single crystals. Acta Mater 61:3445-3455

13. Krooß P, Holzweissig MJ, Niendorf T, Somsen C, Schaper M, Chumlyakov YI, Maier HJ (2014) Thermal cycling behavior of an aged FeNiCoAlTa single-crystal shape memory alloy. Scr Mater. 81:28-31

14. Krooß P, Somsen C, Niendorf T, Schaper M, Karaman I, Chumlyakov Y, Eggeler G, Maier HJ (2014) Cyclic degradation mechanisms in aged FeNiCoAlTa shape memory single crystals. Acta Mater 79:126-137

15. Geng Y, Lee D, Xu X, Nagasako M, Jin M, Jin X, Omori T, Kainuma R (2015) Coherency of ordered $\gamma^{\prime}$ precipitates and thermoelastic martensitic transformation in FeNiCoAlTaB alloys. J Alloy Compd 628:287-292

16. Omori T, Abe S, Tanaka Y, Lee DY, Ishida K, Kainuma R (2013) Thermoelastic martensitic transformation and superelasticity in $\mathrm{Fe}-\mathrm{Ni}-\mathrm{Co}-\mathrm{Al}-\mathrm{Nb}-\mathrm{B}$ polycrystalline alloy. Scr Mater. 69:812-815

17. Chumlyakov YuI, Kireeva IV, Poklonov VV, Pobedennaya ZV, Karama I (2014) The shape-memory effect and superelasticity in single-crystal ferromagnetic alloy FeNiCoAlTi. Tech Phys Lett 40:17 (in Russia)

18. Lee D, Omori T, Kainuma R (2014) Ductility enhancement and superelasticity in Fe-Ni-Co-Al-Ti-B polycrystalline alloy. J Alloy Compd 617:120-123

19. Tseng LW, Ma J, Karaman I, Wang SJ, Chumlyakov YI (2015) Superelastic response of the FeNiCoAlTi single crystals under tension and compression. Scr Mater. 101:1-4

20. Tanaka Y, Kainuma R, Omori T, Ishida K (2015) Alloy design for $\mathrm{Fe}-\mathrm{Ni}-\mathrm{Co}-\mathrm{Al}$-based superelastic alloy. Mater Today 2S:S485-S492

21. Omori T, Watanabe K, Umetsu RY, Kainuma R, Ishida K (2009) Martensitic transformation and magnetic field-induced strain in Fe-Mn-Ga shape memory alloy. Appl Phys Lett 95:082508

22. Zhu W, Liu EK, Feng L, Tang XD, Chen JL, Wu GH, Liu HY, Meng FB, Luo HZ (2009) Magnetic-field-induced transformation in FeMnGa alloys. Appl Phys Lett 95:222512

23. Omori T, Ando K, Okano M, Xu X, Tanaka Y, Ohnuma I, Kainuma R, Ishida K (2011) Superelastic effect in polycrystalline ferrous alloys. Science 333:69-71

24. Omori T, Nagasako M, Okano M, Endo K, Kainuma R (2012) Microstructure and martensitic transformation in $\mathrm{Fe}-\mathrm{Mn}-\mathrm{Al}-\mathrm{Ni}$ shape memory alloy with B2-type coherent fine particles. Appl Phys Lett 101:231907

25. Omori T, Okano M, Kainuma R (2013) Effect of grain size on superelasticity in $\mathrm{Fe}-\mathrm{Mn}-\mathrm{Al}-\mathrm{Ni}$ shape memory alloy wire. APL Mater. 1:032103 
26. Tseng LW, Ma J, Wang SJ, Karaman I, Kaya M, Luo ZP, Chumlykov YI (2015) Superelastic response of a single crystalline FeMnAlNi shape memory alloy under tension and compression. Acta Mater 89:374-383

27. Vollmer M, Segel C, Krooß P, Günther J, Karaman I, Weidner A, Biermann H, Niendorf T (2015) On the effect of gamma phase formation on the pseudoelastic performance of polycrystalline $\mathrm{Fe}-\mathrm{Mn}-\mathrm{Al}-\mathrm{Ni}$ shape memory alloys. Scr Mater. 108:23-26

28. Tseng LW, Ma J, Hornbuckle BC, Karaman I, Thompson GB, Luo ZP, Chumlyakov YI (2015) The effect of precipitates on the superelastic response of [100] oriented FeMnAlNi single crystals under compression. Acta Mater 97:234-244

29. Jia CC, Ishida K, Nishizawa T (1994) Partition of alloying elements between $\gamma(A 1), \gamma^{\prime}\left(L_{2}\right)$, and $\beta(B 2)$ phases in $\mathrm{Ni}-\mathrm{Al}$ base systems. Metall Mater Trans A 25:473

30. Sims CT, Stoloff NS, Hagel WC (eds) (1987) Superalloys II. Willy, New York

31. Watanabe T, Fujii H, Oikawa H, Arai KI (1989) Grain boundaries in rapidly solidified and annealed Fe-6.5 mass\% Si polycrystalline ribbons with high ductility. Acta Metall 37:941-952 